\title{
Critical role of molecular test in early diagnosis of gastric tuberculosis: a rare case report and review of literature
}

\author{
Jun Ma ${ }^{1,2}$, Hongyun Yin ${ }^{1 *}$ and Huikang Xie $e^{1,3}$
}

\begin{abstract}
Backgroud: Early diagnosis of gastric tuberculosis is often challenging because the disease is very rare and its clinical manifestation is nonspecific and misleading. To raise the awareness and emphasize early diagnosis of gastric tuberculosis, we present a case of gastric tuberculosis secondary to pleural and pulmonary tuberculosis.

Case presentation: A 26-year-old woman complained gastric pain for 1 month but showed no other symptoms, who had no previous exposure to tuberculosis.Gastric stromal tumor was originally suspected. However, the pathology of her gastroscopic biopsy of the gastric lesion showed granulomatous lesions and caseating necrosis. Gene sequencing of the biopsy specimen identified deoxyribonucleic acid fragment of Mycobacterium tuberculosis. Chest computed tomography scan revealed nodular shadows in the lesser curvature soft tissue of the stomach, patchy densities and calcified nodular shadows in the upper right lung, bilateral pleural thickening, and calcified pleural nodules. Thus, the diagnosis was gastric tuberculosis secondary to pulmonary and pleural tuberculosis. The patient was hospitalized and treated with the antituberculosis therapy for 1 week. After discharged from the hospital, the patient continued routine antituberculosis therapy for 18 months and was follow-up was normal.Literature search found 22 cases of gastric tuberculosis reported from 2000 to 2016. Review of the 22 cases suggested that polymerase chain reaction has been increasingly used in the recent years in addition to the conventional histopathological and bacteriological approaches.

Conclusion: Clinical presentation of gastric tuberculosis is not specific. When granuloma or caseation is detected on biopsy in patients who are suspected of having gastric malignancy or acid peptic diseases, polymerase chain reaction for Mycobacterium tuberculosis could be used as an available and sensitive diagnostic test in addition to pathology, acid-fast bacilli smear staining and culture.
\end{abstract}

Keywords: Gastric tuberculosis, Diagnosis, Polymerase chain reaction

\section{Background}

The gastrointestinal tract is the sixth most common location for extrapulmonary tuberculosis (TB) [1]. However, gastric TB is very rare because the unique characteristics of the stomach, such as gastric acid, fast gastric emptying, and scarcity of lymphatic tissue in the gastric wall, may protect the organ from TB [2]. Subei et al. have reported that the incidence of gastric $\mathrm{TB}$ is $0.03-$

\footnotetext{
* Correspondence: yinhongyun2004@163.com

${ }^{1}$ Clinic and Research Center of Tuberculosis, Shanghai Key Lab of Tuberculosis, Shanghai Pulmonary Hospital, Tongji University School of Medicine, Shanghai 200433, China

Full list of author information is available at the end of the article
}

$0.21 \%$ in all routine autopsies [3]. In China, the incidence appears higher. Yang et al. found that the incidence of gastric TB in Chinese patients undergoing gastrectomy between 1962 and 2002 in 10 hospitals in northeastern China was $0.37 \%$ [4].

Gastric TB often develops secondary to pulmonary TB [5]. Previous reports suggest that:the frequency of gastric tuberculosis is related to the severity of pulmonary involvement. In the study of Mitchell and Bristol, it was present in $1 \%$ of patients with minimal pulmonary tuberculosis, $4.5 \%$ in those with moderately advanced pulmonary tuberculosis, and $25 \%$ in those with advanced disease [6].Nevertheless, primary gastric TB has been sporadically reported during the past 16 years [7-13]. Here, to promote the awareness of gastric $\mathrm{TB}$ and

(c) The Author(s). 2019 Open Access This article is distributed under the terms of the Creative Commons Attribution 4.0 International License (http://creativecommons.org/licenses/by/4.0/), which permits unrestricted use, distribution, and 
emphasize accurate diagnosis and prompt treatment for the disease, we present a case of gastric TB secondary to pleural and pulmonary $\mathrm{TB}$ and review previous cases that were reported between 2000 and 2016.

\section{Case presentation}

A 26-year-old woman patient was admitted to Shanghai Pulmonary Hospital on December 13, 2013 for constant gastric pain for 1 month. One month before the hospital admission, the patient started to experience gastric pain accompanied with acid reflux for no apparent cause. The pain became worse on an empty stomach. The patient did not present swallowing difficulties, belching, nausea, vomiting blood, black stool, fever, fatigue, diarrhea, or tenesmus at hospital admission. The patient had no previous exposure to tuberculosis.Gastroscopy revealed a hemispherical bulge with smooth surface (Fig. 1a) and two small ulcers on the posterior wall of the lesser curvature of the stomach (Fig. 1b). Endoscopic ultrasound showed hypoechoic masses around the lesion (Fig. 1c), ununiform echo with some area of strong echo inside the lesion, and rich blood flow inside the lesion (Fig. 1d). The lesion was located in the fourth echo layer and showed a dimension of $26 \mathrm{~mm} \times 21.5 \mathrm{~mm}$ (Fig. 1c). The patient was originally suspected to have gastric stromal tumor. The pathology of gastroscopic biopsy displayed acid-fast staining negative, reticular fiber staining negative, periodic acid Schiff staining negative, and ammoniacal silver staining negative. Haematoxylin \& eosin staining of the gastroscopic biopsy specimen showed patches of caseating necrosis and granulomatous inflammation (Fig. 1e and f). Gene sequencing by polymerase chain reaction(PCR)analysis of the gastroscopic biopsy specimen found Mycobacterium tuberculosis (M. TB) deoxyribonucleic acid (DNA) fragments.

Chest computed tomography (CT) scan demonstrated: 1) patchy densities and calcified nodular shadows in the upper right lung (Fig. 1g), suggesting a possible previous lung TB; 2) calcified pleural nodules in the lower right pleural (Fig. 1h); 3) nodular shadows in the lesser curvature soft tissue of the stomach (Fig. 1i). Chest CT-guided percutaneous needle biopsy on the pleural nodules found necrotic tissue and inflammatory cells, The acidfast stain smear was negative, Along with other findings in chest CT and gastric pathology and positive TB-PCR, these pathologic changes may be in favor of TB pleural involvement. Electronic Bronchoscopy showed normal lumen and mucosal membrane. The patient did not have a previous diagnosis of TB. She had normal routine blood and chemistry test results. Tuberculin skin test (TST) showed an induration of $22 \mathrm{~mm} \times 18 \mathrm{~mm}$. M. TB antibody test and T-SPOT.TB test (A30 and B10) were positive. Based on these clinical data, the patient was diagnosed as gastric TB. First acid-fast bacilli smear and culture tests were negative.

The patient was hospitalized and underwent the systematic antitubercular therapy(ATT) HREZ for 1 week ( $0.3 \mathrm{~g}$ once daily oral isoniazid., rifampicin $0.45 \mathrm{~g}$ once a day on an empty stomach, $0.75 \mathrm{~g}$ once daily oral ethambutol, pyrazinamide orally, $0.5 \mathrm{~g}$ three times a day. Oral protection of liver is also given). The patient insisted on an outpatient review every month, with routine blood tests and liver and kidney function tests. After 3 months of anti-tuberculosis treatment, the patient developed gastrointestinal reaction and blurred vision, and the adjustment programme was HRptZLfx,(Isoniazid $0.3 \mathrm{~g} 1$ day orally, rifapentini 0.45 a week twice fasting, pyrazinamide $0.5 \mathrm{~g}$ a day three times, levofloxacin $0.5 \mathrm{~g} 1$ day orally). The above side effects were alleviated.After 6 months of treatment, levofloxacin was discontinued and continued HRptZ treatment. She had normal monthly reexamination of the normal liver and kidney function, and acid-fast bacilli smear and culture tests were negative for every 3 months. The erythrocyte sedimentation rate and $C$ reactive protein were negative before the drug withdrawal. Her gastroscopy showed normal results. Her chest CT scan revealed calcified nodules in the upper right lung (Fig. 1j), bilateral pleural thickening (Fig. 1k), calcified pleural nodules (Fig. 1l), and substantially smaller nodules with some calcification in the lesser curvature (Fig. 11) compared with the chest CT scan results on the hospital admission (Fig. 1g-i). Her sputum acid-fast bacilli smear and culture tests in March and May 2015 showed negative results. The antitubercular therapy was ended in May 2015. Her total treatment course was 18 months.

\section{PCR approach}

Deparaffinisation and DNA extractionTissue sections $5 \mu \mathrm{m}$ thick were cut from paraffin blocks, and 10 sections were placed in $1.5 \mathrm{ml}$ sterile EP tube. The tissues were deparaffinised by adding $1 \mathrm{ml}$ of xylene to each microtube and the samples were mixed gently for $20 \mathrm{~min}$ at $65^{\circ} \mathrm{C}$. The samples were then centrifuged at $13000 \mathrm{rpm}$ for $2 \mathrm{~min}$ and the supernatants were discarded. Residual xylene was removed by washing the samples twice with $1 \mathrm{ml}$ of $100 \%$ ethanol for $5 \mathrm{~min}$ and centrifuging at $13000 \mathrm{rpm}$ for $2 \mathrm{~min}$. The pellets were dried in a speed vacuum, and $200 \mu \mathrm{l}$ of FTL and $25 \mu \mathrm{l}$ of OB Protease (OMEGA). Genomic DNA was isolated using the E.Z.N.A.TM FFPE DNA kit from Omega Biotek Inc. (Norcross, GA, USA) according to the protocol provided by the manufacturer. The contents and purity of the extracted DNA were assayed by measuring absorbance at 260 and $280 \mathrm{~nm}$ using a spectrophotometer.PCR amplificationIS6110 gene is specific for MTBC and 16SrRNA gene is specific for mycobacterium genus. 

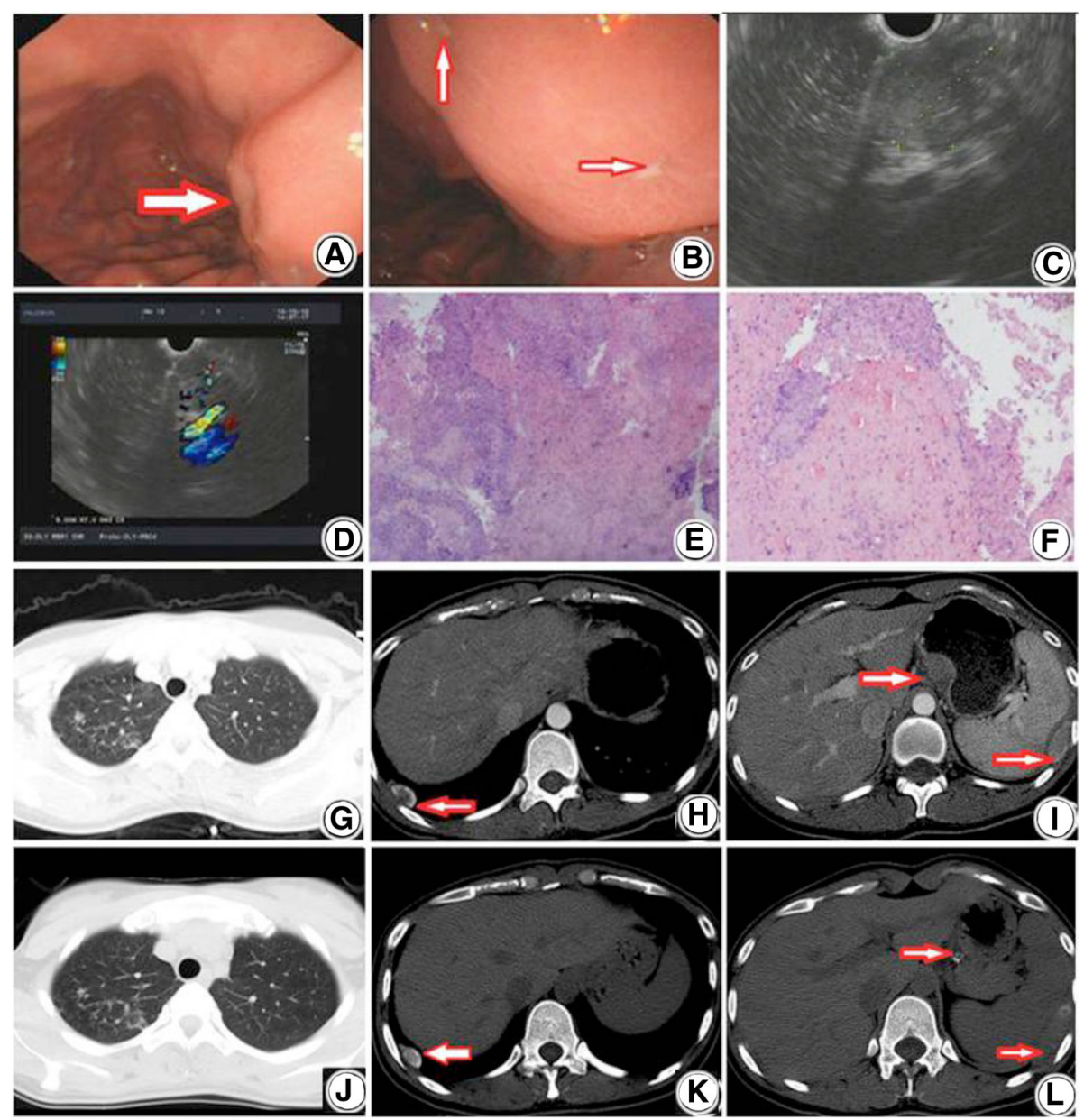

Fig. 1 Images of gastroscopy, endoscopic ultrasound, Haematoxylin Eosin staining, Chest CT scan. a and $\mathbf{b}$. Images of gastroscopy showing a hemispherical bulge with smooth surface (a) and two small ulcers on the posterior wall of the lesser curvature of the stomach (b). $\mathbf{c}$ and $\mathbf{d}$. Images of endoscopic ultrasound showing hypoechoic masses with a size of $26 \mathrm{~mm} \times 21.5 \mathrm{~mm}$ (c) and ununiform echo with some area of strong echo inside the lesion, and rich blood flow inside the lesion (d). e and $\mathbf{f}$. Images of Haematoxylin \& Eosin staining showing patches of caseating necrosis and granulomatous inflammation (e: 40x, f: 100x). g-i. Image of Chest CT scan at hospital admission (December 2013) showing high densities and patchy nodules in the upper right lung $(\mathbf{g})$, calcified pleural nodules in the lower right pleural (h), and soft tissue nodules in the lesser curvature of the stomach (i). $\mathbf{j}$-1. Image of chest CT at the follow-up (May 2015) showing that the patchy nodules in the upper right lung were partially absorbed (j), smaller pleural nodules $(\mathbf{k})$, and substantially smaller nodules with some calcification in the lesser curvature of the stomach and calcified pleural nodules in the lower left pleural (I).

The following primer sets were used for PCR: IS6110 (sense 5 '-CCTGCGAGCGTAGGCGTCGG-3', anti-sense 5' - CCTGCGAGCGTAGGCGTCGG-3'); the product size of IS6110 was $123 \mathrm{bp}$ a. Reactions were run in $25 \mathrm{ul}$ volumes containing $2 \mathrm{ul}$ of sample DNA. The remaining volumes was added using PCR master Mix $(2 \times)$ from Thermo according to the protocol provided by the manufacturer. The amplification program was consisted of initial denaturation at $95^{\circ} \mathrm{C}$ for $5 \mathrm{~min}$, followed by 35 cycles of denaturation at $94^{\circ} \mathrm{C}$ for $45 \mathrm{~s}$, annealing at $60^{\circ} \mathrm{C}$ for $30 \mathrm{~s}$, extension at $72^{\circ} \mathrm{C}$ for $45 \mathrm{~s}$, and a final extension at $72{ }^{\circ} \mathrm{C}$ for $10 \mathrm{~min}$. The PCR products were analyzed by $2 \%$ agarose gel electrophoresis [14].
Summary of previously reported cases from 2000 to 2016 We searched PubMed for the keyword "gastric tuberculosis" and found that 22 cases of gastric TB were reported from 2000 to 2016 [7-13, 15-25]. The summary of these cases is displayed in Table 1 . The patients were 21 to 80 years of age, and the mean age was $38.6 \pm 15.3$ years. The average history of disease were $6.4 \pm 6.06$ months. The shortest is 1 month. Of the 22 cases, $45.5 \%$ $(10 / 22)$ were men; $59.1 \%(13 / 22)$ were primary gastric TB; 31.8\% (7/22) had gastric outlet obstruction (Table 1) . Two cases were gastric TB with concomitant cancer $[18,24]$. PCR was commonly used to diagnose gastric TB since 2011 (Table 1) [8, 9, 15-18]. Most cases 
Table 1 Summary of previously reported cases from 2000 to 2016

\begin{tabular}{|c|c|c|c|c|c|c|c|}
\hline Authors & Year & Age & Sex & Clinical feature & Diagnostic approach & $\begin{array}{l}\text { Treatment } \\
\text { duration }\end{array}$ & $\begin{array}{l}\text { strategy } \\
\text { (combination } \\
\text { of anti-TB drugs) }\end{array}$ \\
\hline Arabi [7] & 2015 & 54 & M & $\begin{array}{l}\text { Primary gastric TB with } \\
\text { outlet obstruction }\end{array}$ & Histopathological confirmation & NA & NA \\
\hline Yaita Hiroki [15] & 2014 & 60 & M & $\begin{array}{l}\text { Gastric TB with systemic } \\
\text { ymphadenopathy }\end{array}$ & $\begin{array}{l}\text { PCR of biopsy specimen was positive } \\
\text { for M. TB }\end{array}$ & NA & NA \\
\hline Moghadam [8] & 2013 & 43 & M & $\begin{array}{l}\text { Primary gastric TB } \\
\text { mimicking gastric cancer }\end{array}$ & $\begin{array}{l}\text { PCR of surgical specimens was positive } \\
\text { for } M \text {. TB. }\end{array}$ & 6 months & 2HREZ/4HR \\
\hline Ecka [16] & 2013 & 31 & M & $\begin{array}{l}\text { Isolated gastric TB with } \\
\text { outlet obstruction }\end{array}$ & $\begin{array}{l}\text { PCR of tissue biopsy was positive } \\
\text { for M. TB. }\end{array}$ & 9 months & 2HREZ/7HR \\
\hline $\operatorname{Lim}[15]$ & 2013 & 38 & $\mathrm{~F}$ & $\begin{array}{l}\text { Gastric TB with a huge } \\
\text { abdominal mass }\end{array}$ & $\begin{array}{l}\text { Endoscopic biopsy specimen was positive } \\
\text { on acid-fast bacillus staining. PCR of the } \\
\text { biopsy specimen was positive for M. TB. }\end{array}$ & $\begin{array}{l}12 \\
\text { months }\end{array}$ & AmMfxPtoCsZ \\
\hline Kang [18] & 2012 & 54 & $\mathrm{~F}$ & $\begin{array}{l}\text { Gastric cancer } \\
\text { concomitant gastric TB }\end{array}$ & $\begin{array}{l}\text { Tuberculosis PCR of the gastric mucosa and } \\
\text { omental lymph nodes was positive for M. TB. }\end{array}$ & NA & NA \\
\hline Ishii [9] & 2011 & 39 & $\mathrm{~F}$ & $\begin{array}{l}\text { Primary gastric TB presenting } \\
\text { as non-healing ulcer and } \\
\text { mimicking Crohn's disease }\end{array}$ & $\begin{array}{l}\text { Respond to empiric ATT. All the test } \\
\text { including PCR showed negative for M. TB. }\end{array}$ & $\begin{array}{l}10 \\
\text { months }\end{array}$ & 2HREZ/8HRE \\
\hline $\begin{array}{l}\text { Mukhopadhyay } \\
{[10]}\end{array}$ & 2010 & 30 & $\mathrm{~F}$ & Isolated gastric TB & $\begin{array}{l}\text { Histopathology revealed granulomatus } \\
\text { inflammation of M. TB }\end{array}$ & 6 months & 2HREZ/4HR \\
\hline $\begin{array}{l}\text { Bandyopadhyay } \\
{[19]}\end{array}$ & 2010 & na & na & $\begin{array}{l}\text { Gastric TB with outlet } \\
\text { obstruction }\end{array}$ & Respond to empiric ATT & NA & NA \\
\hline Baylan [20] & 2009 & 80 & $\mathrm{~F}$ & Primary gastric TB & $\begin{array}{l}\text { PCR of biopsy specimen was positive } \\
\text { for M. TB }\end{array}$ & 6 months & 2HREZ/4HR \\
\hline Khan [11] & 2008 & 29 & M & Primary gastric fundus TB & $\begin{array}{l}\text { Endoscopic biopsy showed caseating } \\
\text { granulomas with acid-fast bacilli in the } \\
\text { ulcerative mass. }\end{array}$ & 6 months & 6HREZ \\
\hline Talukdar [21] & 2006 & 30 & $\mathrm{~F}$ & $\begin{array}{l}\text { Gastric TB presenting as linitis } \\
\text { plastica and outlet obstruction }\end{array}$ & $\begin{array}{l}\text { Endoscopic biopsy specimens showed } \\
\text { caseating granulomas and positive for acid } \\
\text { fast bacilli staining. }\end{array}$ & NA & HREZ \\
\hline Kim [22] & 2005 & 21 & $\mathrm{~F}$ & $\begin{array}{l}\text { Gastric TB presenting as a } \\
\text { submucosal tumor }\end{array}$ & $\begin{array}{l}\text { Histopathologic examination of the surgical } \\
\text { specimens revealed chronic granulomatous } \\
\text { inflammation with caseation necrosis. PCR for } \\
\text { M. TB with the surgical specimens was positive. }\end{array}$ & 3 months & 3HRE \\
\hline Sharma [23] & 2004 & 21 & $\mathrm{~F}$ & Gastric TB with a perforation & $\begin{array}{l}\text { Histopathological examination revealed } \\
\text { tuberculous granulation and acid-fast bacilli } \\
\text { in the ulcer. }\end{array}$ & 17 & NA \\
\hline \multirow[t]{5}{*}{$\begin{array}{l}\text { Amarapurkar } \\
{[12]}\end{array}$} & \multirow[t]{5}{*}{2003} & 32 & $\mathrm{~F}$ & $\begin{array}{l}\text { Primary gastric TB with } \\
\text { outlet obstruction }\end{array}$ & $\begin{array}{l}\text { Lymph node biopsies showed positive for } \\
\text { acid-fast bacilli staining. }\end{array}$ & 9 months & 2HREZ/7HR \\
\hline & & 53 & M & $\begin{array}{l}\text { Primary gastric TB with } \\
\text { outlet obstruction }\end{array}$ & $\begin{array}{l}\text { Histopathology of the lymph node revealed } \\
\text { caseating granuloma }\end{array}$ & 9 months & 2HREZ/7HR \\
\hline & & 23 & $\mathrm{~F}$ & $\begin{array}{l}\text { Primary gastric TB with } \\
\text { outlet obstruction }\end{array}$ & $\begin{array}{l}\text { Histology demonstrated caseating granuloma } \\
\text { with the presence of acid fast bacilli. }\end{array}$ & 9 months & 2HREZ/7HR \\
\hline & & 32 & M & Primary gastric TB & $\begin{array}{l}\text { Endoscopic biopsy revealed caseating epitheloid } \\
\text { granuloma with Langhan's giant cells. }\end{array}$ & 9 months & 2HREZ/7HR \\
\hline & & 30 & M & Primary gastric TB & $\begin{array}{l}\text { Endoscopic biopsy showed multiple tubercular } \\
\text { caseating granulomas. }\end{array}$ & 9 months & 2HREZ/7HR \\
\hline Khan [24] & 2003 & na & na & $\begin{array}{l}\text { Gastric TB with concomitant } \\
\text { stromal tumor of stomach }\end{array}$ & & NA & NA \\
\hline Wig [13] & 2000 & 25 & M & $\begin{array}{l}\text { Isolated gastric TB presenting } \\
\text { as massive hematemesis }\end{array}$ & Histopathological examination & NA & NA \\
\hline Chetri [25] & 2000 & 46 & M & $\begin{array}{l}\text { Gastric TB presenting as } \\
\text { non-healing ulcer }\end{array}$ & $\begin{array}{l}\text { Endoscopic biopsy specimens showed caseating } \\
\text { granulomas and positive for acid fast bacilli } \\
\text { staining. }\end{array}$ & NA & NA \\
\hline
\end{tabular}

$A T T$ antitubercular therapy, $P C R$ polymerase chain reaction, $M$. TB Mycobacterium tuberculosis, $H$ isoniazid, $R$ rifampicin, $E$ ethambutol, $Z$ pyrazinamide, $A m$ kanamycin, Mfx moxifloxacin, Pto prothionamide, Cs cycloserin, NA not avalaible 
presented caseating granuloma in endoscopic biopsy specimens or surgical specimens (Table 1). Notably, a few cases did not show confirmed diagnosis of gastric TB but responded well to empiric ATT (Table 1) [9, 19]. All the patients survived and respond well to routine ATT.

\section{Discussion and conclusion}

Gastric TB likely occurs at the pyloric antrum because of an increased amount of lymphoid tissue in the pyloric antrum compared with other area in the stomach. Although normal physiological features of the stomach may have some protective effects, abnormal gastric conditions, such as injury, erosion, and/or ulcer in the gastric mucosa, a reduction in gastric acid, and delayed gastric emptying may extend the residence time of $M$. $\mathrm{TB}$ in the stomach and thus increase the risk for gastric TB. Four possible routes of infection have been proposed: 1) a direct gastric mucosal infection, for example, swallowing M. TB-contaminated sputum or food; 2) hematogenous dissemination of M. TB; 3) M. TB-spread via lymphatic system; 4) infection from adjacent $M$. TBinfected abdominal organs, such as pancreatic and/or splenic TB [2]. Gastric TB is often thought to develop secondary to pulmonary or other extrapulmonary TB [5]. In the current study, our patient's chest CT scan showed high-density patchy calcified nodules in upper right lung and calcified pleural nodules, suggesting that her gastric TB appeared to be secondary to pulmonary and pleural TB for years or more. Thus, screening for possible pulmonary and extrapulmonary TB could facilitate an accurate diagnosis of gastric TB.

The current study also found that $59.1 \%$ of the previous cases reported between 2000 and 2016 were primary gastric TB. Diagnose of primary gastric TB is often challenging because the clinical presentation of gastric $\mathrm{TB}$ varies greatly and lacks specific features. Salpeter et al. suggested that only approximately $50 \%$ of primary or isolate gastric TB might be diagnosed accurately [26]. The most frequent complaint associated with gastric TB is chronic epigastric pain, which usually lasts couple months. Patients often also present other symptoms, such as vomiting, pyloric obstruction, diarrhea, constipation, fever, weight loss, and fatigue. In addition, patients with gastric TB frequently develop gastric outlet obstruction. In the current study, we found $31.8 \%(7 / 22)$ of previous cases had outlet obstruction [2, 7, 12, 16, 19, 21]. Notably, in the current study, gastric pain was the only obvious complaint of our patient.

Gastric TB is sometimes misdiagnosed as gastric cancer or tumor, because its clinical presentations resemble those of gastric cancer, particularly because of the presence of an epigastric mass in both conditions. Kim et al. have demonstrated a case of gastric TB presenting as a submucosal tumor, which was originally suspected as stromal tumor but later confirmed as gastric TB based on the chronic granulomatous inflammation with caseation necrosis in the resected tissue and positive PCR for $M$. TB of the resected tissue [22]. In the current study, gastric stromal tumor was originally suspected. Concomitant gastric cancer and TB may even further complicate the diagnosis of gastric TB. Kang et al. have reported a case of coexisting $\mathrm{TB}$ and gastric adenocarcinoma [18], and Khan et al. have shown a simultaneous stromal tumor of stomach and gastric TB [24]. Kim et al. have recommended that gastric $\mathrm{TB}$ should be suspected if patients exhibit TB in other organs, positive tuberculin test, an obvious abdominal mass, fistula formation, and duodenum involvement [22].

Early diagnosis of gastric TB is critical to improve outcomes. If left untreated, gastric TB could deteriorate and ultimately lead to gastric perforation. Sharma et al. have reported a patient with tuberculous gastric perforation, who received emergency distal gastrectomy and postoperative ATT and survived eventually [23]. However, the four cases of tuberculous gastric perforation, which were reported between 1948 and 2003, all died [24]. Currently, histological, bacteriological, and molecular biological approaches have been used to diagnose gastric TB.

Gastroscopic observation and biopsy remain the most commonly used approaches to diagnose gastric TB. The presence of caseating granuloma or positive acid-fast bacilli staining on the lesion tissues are usually considered as valid clinical evidence for gastric TB [5]. However, acid-fast bacilli staining sometimes show false negative results. In fact, our patient showed negative acid-fast bacilli staining. Ishii et al. have demonstrated a patient with primary gastric TB showing negative acid-fast bacilli staining, but the patient responded to empiric ATT effectively [9]. Baylan et al. have also shown that a patients presented negative acid-fast bacilli staining and negative bacterial culture of the biopsy specimen, whereas had positive PCR for M. TB [20]. Moreover, collecting sufficient and accurate specimens during gastroscopic biopsy sometime is challenging because granulomas are often located underneath the gastric mucosa, which is difficult to reach during a gastroscopic biopsy procedure. Thus, most patients may have to undergo surgical intervention when gastroscopic biopsy fails to support an accurate diagnosis. The subsequent histopathological examination of the surgical samples can usually confirm a diagnosis of gastric TB.

Notably, molecular biological technique, such as polymerase chain reaction (PCR) and DNA sequencing, have been increasingly used in the recent years [8, 9, 15-18]. In 2005, the report by Kim et al. appeared to be the first case of using PCR to detect M.TB in surgical specimens [22]. In 2009, Baylan et al. first reported a successful application of PCR on gastroscopic biopsy specimen to diagnose gastric TB [20]. PCR was used to diagnose 
gastric TB in 7 of the 10 cases that were reported from 2009 to 2016 [7-10, 15-20]. In the current study, gene sequencing of gastroscopic biopsy specimen showed positive for M. TB. PCR appears to be more frequently used to diagnose intestinal TB [27-29]. Balamurugan et al. found that the sensitivity and specificity of fecal PCR to diagnose intestinal TB were 88.8 and $100 \%$, respectively [28]. The diagnostic performance of PCR in gastric TB remains to be determined. In the current study, we found that PCR of biopsy or surgical specimens was performed in 8 cases; 7 of them (87.5\%) showed positive M.TB; only one case had false negative result [9]. False negative is often caused by insufficient tissue samples. Therefore, it is very important to obtain high-quality specimens. It is often relatively easy to get pathological diagnosis and PCR amplification. However, the diagnosis rate of gastric tuberculosis is lower in gastroscope. The reason may be that the granuloma is often confined to the mucous membrane and the gastroscopy biopsy is mostly taken from the surface of the lesion, and it is not easy to reach the central position of the lesion. Fewer effective specimens were obtained, so false negative results were often obtained.In this case, endoscopic ultrasonography was performed at the same time in the endoscopic examination, and the biopsy site was accurately positioned to obtain high quality pathological specimens. Compared with other diagnostic methods, PCR appears to provide results rapidly, and thus may be a promising method for early diagnosis of gastric TB.

Clinical presentation of gastric tuberculosis is not specific.When granuloma or caseation is detected on biopsy in patients who are suspected of having gastric malignancy or acid peptic diseases, PCR for Mycobacterium tuberculosis could be used as an available and sensitive diagnostic test in addition to pathology, acid-fast bacilli smear staining and culture.

\section{Endnotes}

Yes.

\section{Abbreviations}

ATT: Antitubercular therapy; CT: Computed tomography;

DNA: Deoxyribonucleic acidcomputed tomography; E: Ethambutol;

H: Isoniazid; Lfx: Levofloxacin; M. TB: Mycobacterium tuberculosis;

PCR: Polymerase chain reaction; R: Rifampicin; Rpt: Rifapentini;

TB: Tuberculosis; TST: Tuberculin skin test; Z: Pyrazinamide

\section{Acknowledgements}

We thanks all of authors work and our patients's cooperation.

\section{Authors' contributions}

Involvement in conception, hypothesis, and design of the study: JM, HY; acquisition of the data: JM; Pathological diagnosis:HX; analysis and interpretation of the data: JM, HY; substantial involvement in the writing and/or revision of the article: JM, HY. All authors have read and approved the manuscript, and ensure that this is the case.

\section{Funding}

The authors have no support or funding to report.

\section{Availability of data and materials}

The datasets used and/or analysed during the current study are available from the corresponding author on reasonable request.

Ethics approval and consent to participate

Yes, it was approved by Shanghai Pulmonary Hospital Ethics Committee.

\section{Consent for publication}

I have clearly stated that written informed consent was obtained from the patient for publication of this Case Report and any accompanying images.

\section{Competing interests}

The authors declare that they have no competing interests.

\section{Author details}

${ }^{1}$ Clinic and Research Center of Tuberculosis, Shanghai Key Lab of Tuberculosis, Shanghai Pulmonary Hospital, Tongji University School of Medicine, Shanghai 200433, China. ${ }^{2}$ Department of Tuberculosis and Shanghai Key Lab of Tuberculosis, Shanghai Pulmonary Hospital Affiliated to Tongji University, 507 Zhengmin Road, Shanghai 200433, China. ${ }^{3}$ Pathology department, Shanghai Pulmonary Hospital Affiliated to Tongji University, 507 Zhengmin Road, Shanghai 200433, China.

Received: 19 April 2018 Accepted: 26 June 2019

Published online: 05 July 2019

\section{References}

1. Mehta JB, Dutt A, Harvill L, Mathews KM. Epidemiology of extrapulmonary tuberculosis. A comparative analysis with pre-AIDS era. Chest. 1991;99:1134-8.

2. Gupta B, Mathew S, Bhalla S. Pyloric obstruction due to gastric tuberculosis: An endoscopic diagnosis. Postgrad Med J. 1990;66:62-5.

3. Subei I, Attar B, Schmitt G, Levendoglu H. Primary gastric tuberculosis: a report and literature review. Am J Gastroenterol. 1987;82:769-72.

4. Yang WL, Jin ZX, Zhang HM, Zhao Z, Zhang JG, Liang CL, Li JW, Wang TS, Sun YC, Fan ZX. Gastric tuberculosis: an analysis of 75 cases. Chin J Gastrointes Surg. 2003;6:397-9.

5. Chazan Bl, Aitchison JD. Gastric tuberculosis. Brit Med J. 1960;2:1288-90.

6. Mitchell R, Bristol L. Intestinal tuberculosis: analysis of 346 cases diagnosed by routine intestinal radiography on 5529 admissions for pulmonary tuberculosis. Am J Med Sci. 1954;227:241-9.

7. Arabi NA, Musaad AM, Ahmed EE, Ibnouf MM, Abdelaziz MS. Primary gastric tuberculosis presenting as gastric outlet obstruction: a case report and review of the literature. J Med Case Rep. 2015;9:265.

8. Ghadimi Moghadam A, Alborzi A, Pouladfar G, Monabati A. Primary gastric tuberculosis mimicking gastric cancer: a case report. J Infect Dev Ctries. 2013:7:355-7.

9. Ishii N, Furukawa K, Itoh T, Fujita Y. Primary gastric tuberculosis presenting as non-healing ulcer and mimicking Crohn's disease. Intern Med. 2011;50: 439-42.

10. Mukhopadhyay M, Rahaman QM, Mallick NR, Khan D, Roy S, Biswas N. Isolated gastric tuberculosis: a case report and review of literature. Indian J Surg. 2010;72:412-3.

11. Khan FY, AlAni A, Al-Rikabi A, Mizrakhshi A, Osman M-M. Primary gastric fundus tuberculosis in immunocompetent patient: a case report and literature review. Braz J Infect Dis. 2008;12:453-5.

12. Amarapurkar DN, Patel ND, Amarapurkar AD. Primary gastric tuberculosis-report of 5 cases. BMC Gastroenterol. 2003;3:6.

13. Wig JD, Vaiphei K, Tashi M, Kochhar R. Isolated gastric tuberculosis presenting as massive hematemesis: report of a case. Surg Today. 2000;30: 921-2.

14. Parashar D, Chauhan DS, Sharma VD, et al. Applications of real-time PCR technology to mycobacterial research[J]. Indian J Med Res. 2006;124(4):385-98.

15. Yaita H, Nakamura S, Kurahara K, Morishita T, Kochi S, Oshiro Y, Hamaguchi N, Fuchigami T. Gastric tuberculosis resembling depressed type, early gastric cancer. Endoscopy. 2014;46(Suppl 1 UCTN):E669-70.

16. Ecka RS, Wani ZA, Sharma M. Gastric tuberculosis with outlet obstruction: a case report presenting with a mass lesion. Case Rep Med. 2013;2013:169051.

17. Lim JU, Kim YH, Choi CW, Lee JH. Gastric tuberculosis presenting with a huge abdominal mass. Singap Med J. 2013;54:e244-6.

18. Kang HJ, Lee YS, Jang YJ, Mok YJ. Gastric cancer and concomitant gastric tuberculosis: a case report. J Gastric Cancer. 2012;12:254-7. 
19. Bandyopadhyay G, Lahiri S, Ghosh S. Gastric tuberculosis - a diagnostic dilemma. J Indian Med Assoc. 2010;108:875.

20. Baylan O, Kilciler G, Albay A, Tuzun A, Kisa O, Dagalp K. Polymerase chain reaction based diagnosis of primary gastric tuberculosis in an 80-year-old woman: a case report and review of the literature. New Microbiol. 2009;32:217-21.

21. Talukdar R, Khanna S, Saikia N, Vij JC. Gastric tuberculosis presenting as linitis plastica: a case report and review of the literature. Eur I Gastroenterol Hepatol. 2006;18:299-303.

22. Kim SH, Park JH, Kang KH, Lee JH, Park CK, Cho CM, Tak WY, Kweon YO, Kim SK, Choi YH, et al. Gastric tuberculosis presenting as a submucosal tumor. Gastrointest Endosc. 2005;61:319-22.

23. Sharma D, Gupta A, Jain BK, Agrawal V, Dargan P, Upreti L, Arora V. Tuberculous gastric perforation: report of a case. Surg Today. 2004;34:537-41.

24. Khan S, Asghar RG, Mirza MH, Khan TN. Gastric tuberculosis with concomitant stromal tumour of stomach (GIST). J Coll Physicians Surg Pak. 2003;13:48-50

25. Chetri K, Prasad KK, Jain M, Choudhuri G. Gastric tuberculosis presenting as non-healing ulcer: case report. Trop Gastroenterol. 2000;21:180-1.

26. Salpeter SR, Shapiro RM, Gasman JD. Gastric tuberculosis presenting as fever of unknown origin. West J Med. 1991;155:412-3.

27. Amarapurkar DN, Patel ND, Amarapurkar AD, Agal S, Baigal R, Gupte $P$. Tissue polymerase chain reaction in diagnosis of intestinal tuberculosis and Crohn's disease. J Assoc Physicians India. 2004;52:863-7.

28. Balamurugan R, Venkataraman S, John KR, Ramakrishna BS. PCR amplification of the IS6110 insertion element of Mycobacterium tuberculosis in fecal samples from patients with intestinal tuberculosis. $J$ Clin Microbiol. 2006;44:1884-6.

29. Gan HT, Chen YQ, Ouyang Q, Bu H, Yang XY. Differentiation between intestinal tuberculosis and Crohn's disease in endoscopic biopsy specimens by polymerase chain reaction. Am J Gastroenterol. 2002;97:1446-51.

\section{Publisher's Note}

Springer Nature remains neutral with regard to jurisdictional claims in published maps and institutional affiliations.

Ready to submit your research? Choose BMC and benefit from:

- fast, convenient online submission

- thorough peer review by experienced researchers in your field

- rapid publication on acceptance

- support for research data, including large and complex data types

- gold Open Access which fosters wider collaboration and increased citations

- maximum visibility for your research: over $100 \mathrm{M}$ website views per year

At $\mathrm{BMC}$, research is always in progress.

Learn more biomedcentral.com/submissions 